AN. MED INTERNA (Madrid) Vol. 20, N. ${ }^{\circ} 10$, pp. 532-533, 2003

\title{
Síndrome antifosfolípido. Utilidad de la ecocardiografía transesofágica
}

\author{
J. I. CERVERA MIGUEL, V. NAVARRO IBÁÑEZ, E. CALABUIG MUÑOZ, \\ P. TORDERA HIGÓN, M. MONTERO ALONSO
}

\author{
Servicio de Medicina Interna y Unidad de Enfermedades Infecciosas. \\ Hospital Universitario La Fe. Valencia
}

\author{
ANTIPHOSPHOLIPID SYNDROME. THE USE OF TRANSESOPHA- \\ GIC ECHOCARDIOGRAPHY
}

\begin{abstract}
RESUMEN
El síndrome antifosfolípido (SAF) es una alteración inmune que produce trombosis venosas y arteriales, accidente cerebrovascular, aborto recurrente, anemia hemolítica, trombopenia y un sinfín de manifestaciones de órgano. El SAF es una entidad asociada en ocasiones al lupus eritematoso sistémico pudiendo también ser detectado sin enfermedad subyacente de base. El trastorno es debido a la presencia de unas inmunoglobulinas (IgG, IgA, IgM o una combinación de ellas) que adoptan una configuración hexagonal cuando se incuban a $37^{\circ}$. En el SAP es relativamente frecuente encontrar lesiones cardiacas como endocarditis no verrugosa, lesiones valvulares (especialmente de la válvula mitral), enfermedad microvascular cardiaca y mayor riesgo de trombosis a este nivel, mixomas que pueden inducir una inflamación sistémica en relación a la producción de anticuerpos antifosfolípidos , trombos intracardiacos y cardiopatias congénitas.

Presentamos el caso de una mujer con SAP asociado a comunicación interauricular que había debutado anteriormente con tromboembolismo pulmonar y accidente cerebrovascular y que pudo ser diagnosticada tras examen con ecografía transesofágica. Proponemos el examen con esta técnica en pacientes con SAP aunque la ecocardiografía con doppler sea normal. Así podremos descartar lesiones cardiacas que puedan además ser causa de fenómenos embolígenos.
\end{abstract}

PALABRAS CLAVE: Síndrome antifosfolípido. Cardiopatía. Anticuerpos antifosfolípidos.

\begin{abstract}
Antiphospholipid syndrome (APS) is defined by the presence of arterial and venous thromboses, recurrent fetal death, cerebrovascular accidents, hemolytic anaemia, thrombocytopenia and various other manifestations in different organs. APS is a clinical entity that can appear commonly alongside systemic lupus erithemathous on it can occur as a primary disease. The syndrome is defined by the presence of antiphospholipid antibodies in serum, a group of immunoglobulins (IgG, IgM, IgA or an mixture of them) that adopt an hexagonal configuration when they are incubated at $37^{\circ} \mathrm{C}$. In APS, it is rather common to find cardiac lesions such as non-verrucous endocarditis, valvular lesions (especially of the mitral valve), microvascular cardiac disease and more risk of thrombosis at this level, myxomas that could be the cause of a systemic inflammation in relation to the production of antiphospholipid antibodies, intracardiac thrombii and congenital heart disease.

We present the case of a woman with APS associated with interauricular communication whose initial diagnosis were pulmonary thromboembolism and cerebrovascular stroke. We were able to diagnose the cardiac abnormality by the use of transesophagic echocardiography. We propose the use of this imaging technique for patients with APS even though the transthoracic Doppler echocardiography was found to be normal. In this way we will be able to rule out cardiac lesions which could also be the cause of embolic manifestations.
\end{abstract}

KEY WORDS: Antiphospholipid syndrome. Cardiophatic. Antibody antifosfolipids.

Cervera Miguel JI, Navarro Ibáñez V, Calabuig Muñoz E, Tordera Higón P, Montero Alonso M. Síndrome antifosfolípido. Utilidad de la ecocardiografía transesofágica. An Med Interna (Madrid) 2003; 20: 532-533.

\section{INTRODUCCIÓN}

El síndrome antifosfolípido (SAF) es una entidad que se manifiesta clínicamente por trombosis venosas y arteriales, accidente cerebrovascular, aborto recurrente, anemia hemolítica, trombopenia y un sinfín de manifestaciones de órgano (1). El síndrome es debido a la presencia de unas inmunoglobulinas (IgG, IgA, IgM o una combinación de ellas) que pueden ser detectadas mediante técnicas de ELISA y que adoptan una configuración hexagonal cuando se incuban a $37^{\circ}(2)$. El SAP puede ser tratado con el uso de aspirina y dicumarínicos (3) habiéndose propugnado últimamente en casos seleccionados la pauta con inmunoglobulinas (4).

Presentamos el caso de una mujer con SAP asociado a comunicación interauricular que había debutado anteriormente con tromboembolismo pulmonar y accidente cerebrovascular y que pudo ser diagnosticada tras examen con ecografía transesofágica.

Trabajo aceptado: 28 de enero de 2003 


\section{CASO APORTADO}

Mujer de 32 años con antecedentes de ulcus duodenal y cefaleas que sufrió un tromboembolismo pulmonar hace 5 años tras su primer parto.

Tenia dos hijos sin historia previa de abortos. A los cinco años del tromboembolismo tuvo un ictus con paresia facial, afasia e hipoestesia en miembro superior derecho. La TAC mostró dos áreas de infarto. Inició tratamiento con antiagregantes.

Seis meses después desarrolló un nuevo accidente cerebrovascular de mayor duración. Se manifestó con paresia de miembro superior derecho, afasia y parálisis facial transitoria. Una RM objetivó una nueva área de infarto. La exploración física fue normal. Dos tandas de hemocultivos fueron estériles. Se realizó ECG y ecocardiograma doppler sin mostrar alteraciones.

El estudio hematológico mostró: $\mathrm{Hb} 13 \mathrm{~g} / \mathrm{dl}$, plaquetas $135.000 / \mathrm{mm}^{3}$ y leucocitos $7.800 / \mathrm{mm}^{3}$. Función renal y examen de orina normal. Bioquímica básica incluyendo colesterol y triglicéridos normal. ANAs positivos a 1/50 con antiDNA negativo. RPR negativo. Anticoagulante lúpico y anticuerpos anticardiolipina positivos por ELISA. La determinación de proteína $\mathrm{C}, \mathrm{S}$ y antitrombina III fueron normales.

Un ecocardiograma transesofágico mostró una comunicación interauricular. Fue intervenida con cierre del defecto y se inició tratamiento con dicumarínicos y prednisona. En la actualidad se encuentra asintomática.

\section{DISCUSIÓN}

El SAP es una entidad asociada en ocasiones al lupus eritematoso sistémico pudiendo también ser detectado sin enfermedad subyacente de base (5). Clínicamente da lugar a muchas manifestaciones de órgano: afectación neurológica (ictus, síndrome de Sneddon, mielitis transversa, síndrome de Guillén Barré...), alteración neumológica (hipertensión pul- monar, tromboembolismo, distrés y hemorragia alveolar), lesiones cutáneas (úlceras, isquemias distales y nódulos), trombosis venosas y arteriales, infartos placentarios y abortos recurrentes, insuficiencia renal, infarto hepático, etc. En algunas series la forma de presentación más frecuente es la trombosis venosa profunda, sobre todo de miembros inferiores (6).

En el SAP es relativamente frecuente encontrar lesiones cardiacas (7). Se describen endocarditis no verrugosa (8) y lesiones valvulares (especialmente de la válvula mitral) (9). En un estudio comparativo con pacientes sin enfermedad de base se encontraron lesiones valvulares en un $38 \%$ comparado con un $4 \%$ en el grupo control $(\mathrm{p}<0,001)(10)$.También se relaciona con enfermedad microvascular cardiaca y mayor riesgo de trombosis a este nivel $(11,12)$. La aparición de mixomas a nivel cardiaco puede inducir una inflamación sistémica en relación a la producción de anticuerpos antifosfolípidos y otros mediadores inflamatorios (como la IL-6) $(13,14)$. Otras lesiones ocupantes de espacio que aparecen en este síndrome con frecuencia son los trombos intracardiacos, los cuales pueden producir embolismo cerebral secundario $(15,16)$.

En relación a cardiopatías congénitas, como ocurre en el caso que presentamos, se ha visto que pueden asociarse al síndrome antifosfolípido (17) y en ocasiones originar una situación "catastrófica" (18).

Presentamos el caso de una mujer que cumplía criterios de SAP, que pudo ser diagnosticada mediante ecografía transesofágica de una comunicación interauricular ignorada con el examen clínico y un eco doppler transtorácico.

En base al caso presentado, proponemos el examen con estudio de ecocardiografía transesofágica en pacientes con SAP aunque la ecocardiografía con doppler sea normal. Así podremos descartar lesiones cardiacas que puedan además ser causa de fenómenos embolígenos.

\section{BIBLIOGRAFÍA}

1. Alarcón-Segovia D. Clinical manifestations of the antiphospholipid syndrome. J Rheumatol 1992; 19: 1778-81.

2. Diez-Ewald M. Antiphospholipid antibodies. Rev Invest Clin 1993; 34 $143-58$.

3. Cowchock FS, Reece EA, Balaban D, Branch DW, Plouffe L. Repeated fetal losses associated with antiphospholipid antibodies: a collaborative randomized trial comparing prednisone with low-dose heparin treatment. Am J Obstet Gynecol 1992; 166: 1318-23.

4. Kaaja R, Julkunen H, Ammala P, Palosuo T, Kurki P. Intravenous inmunoglobulin treatment of pregnant patients with recurrent pregnancy losses associated with antiphospholipid antibodies. Acta Obstet Gynecol Scand 1993; 72: 63-6.

5. Anónimo. Thrombosis and thrombocytopenia in antiphospholipid syndrome (idiopathic and secundary to SLE): first report the Italian Registry. Italian Registry of Antiphospholipid Antibodies (IR-APA). Haematologica 1993; 78: 313-18.

6. Calvo Romero JM, Bureo Dacal JC, Ramos Salado JL, Bureo Dacal P, Pérez Miranda M. Síndrome antifosfolipídico primario: características y evolución de una serie de 17 casos. An Med Interna (Madrid) 2002; 19: 226-29.

7. Kaplan SD, Chartash EK, Pizzarello RA, Furie RA. Cardiac manifestation of the antiphospholipid syndrome. Am Heart J 1992; 124: 1331-38.

8. Font J, Cervera R, Pare C, Lopez-Soto A, Pallares L, Azqueta M, Khamashta MA. Non-infective verrucous endocarditis in a patient with "prymary antiphospholipid syndrome. Br J Rheumatol 1991; 30: 305-7.

9. Brenner B, Blumenfeld Z, Markiewicz W, Reisner SA. Cardiaca involvement in patients wiyh primary antiphospholipid syndrome. J Am Coll

Cardiol 1991; 18: 931-36

10. Cervera R, Khamashta MA, Font J, Reyes PA, Vianna JL, López-Soto, et al. High prevalence of significant heart valve lesions in patients with the "primary" antiphospholipid syndrome. Lupus 1991; 1: 43-47.

11. Lagana B, Baratta L, Tubani L. Myocardial infarction with normal coronary arteries in a patient with primary antiphospholipid syndromecase report and literature review. Angiology 2001; 52: 785-8.

12. Lauwerys BR, Lambert M, Vanoverschelde JL, Cosyns JP, Houssian FA. Myocardial microangiopathy associated with antiphospholipid antibodies. Lupus 2001; 10: 123-5.

13. Salobir B, Sabovic M, Kozelj M. Increased levels of antiphospholipid antibodies in a woman with left atrial myxoma and systemic embolims. Lupus 2001; 10: 815-7.

14. Quintanilla S, Ferrer S, Bravo M. Myxoma and antiphospholipid antibodies syndrome. Rev Med Chil 1998; 126: 670-6.

15. Casanovas M, Pare C, Azqueta M, Josa M, Font J, Sanz G. Intracardial thrombosis and primary antiphospholipid syndrome. A familiar case. Rev Esp Cardiol 2001; 54: 1005-9.

16. Cham-Lam PD, Bolton JW, Tak T. Space-ocuping lesion in the right ventricle of a patient with antiphospholipid syndrome. J Heart Valve Dis 2001; 10: 399-402.

17. Martínez-Lavin M, Fonseca C, Amigo MC, Nava A, Reyes PA, RuizArguelles A. Antiphospholipid syndrome in patients with cyanotic congenital heart disease. Clin Esp Rheumatol 1995; 13: 489-91.

18. Okura H, Tomon M, Wishiyama S, Yoshikawa T. Patent foramen ovale and "catastrophic" antiphospholipid syndrome. Intern Med 2000; 39: 83. 